\section{Case Reports in Ophthalmology}

Case Rep Ophthalmol 2017;8:425-428

This article is licensed under the Creative Commons Attribution-NonCommercial 4.0 International License (CC BY-NC) (http://www.karger.com/Services/OpenAccessLicense). Usage and distribution for commercial purposes requires written permission.

\title{
Primary Corneoscleral Cyst in a Pediatric Patient
}

\author{
Charudutt Kalamkar Amrita Mukherjee \\ Shri Ganesh Vinayak Eye Hospital, Raipur, India
}

\section{Keywords}

Corneoscleral cyst $\cdot$ Pediatric patients $\cdot$ Surgical excision

\begin{abstract}
Purpose: Primary corneoscleral cyst is a rare disease occurring in the pediatric age group. We report a case of corneoscleral cyst with visual diminution. Methods: We conducted a case report. Results: A 7-year-old girl presented with corneal opacity in the left eye. Examination revealed a corneoscleral cyst. The corneal part of the cyst involved visual axis. Surgical excision with a scleral graft was performed, leading to an improvement in visual acuity. No recurrences were observed until the last follow-up at 18 months. Conclusions: Corneoscleral cyst should be considered in the differential diagnosis of cystic ocular surface disorders in the pediatric age group.

(C) 2017 The Author(s)

Published by S. Karger AG, Basel
\end{abstract}

\section{Introduction}

Corneoscleral cyst is a rare pathology arising due to anomaly in the corneoscleral development. It most commonly presents during the first decade of life and is centered on the limbus. We report a pediatric case with a primary corneoscleral cyst treated successfully with excision and scleral patch grafting. 


\section{Case Reports in Ophthalmology}

\section{Case Presentation}

A 7-year-old girl presented with a slowly progressive corneal opacity in the left eye (OS). The parents first noticed opacity 1 year before, which slowly increased in size. The patient also had gradual diminution of vision for the past 6 months. The decrease in vision was not associated with any other ocular symptoms such as pain, redness, watering, or discharge. There was no history of trauma to the affected eye or contact lens usage. The patient did not have any complaints in the other eye and had not undergone any treatment for the pathology.

OS examination revealed an intrastromal corneal cyst involving the nasal half of cornea and covering the pupillary axis (Fig. 1a). It measured $8 \mathrm{~mm}$ (vertical) by $6 \mathrm{~mm}$ (horizontal). It seemed to arise from a smaller-sized, intrascleral cyst ( $3 \mathrm{~mm}$ by $2 \mathrm{~mm}$; Fig. 1a, c). The conjunctiva was freely mobile over the intrascleral portion of the cyst. The corneal cyst was filled with turbid fluid with multiple opaque particles floating in it. The surrounding stroma outside the cyst margin was clear. There was absence of corneal vascularization or any signs of trauma. The anterior chamber was well formed and clear. The rest of the anterior segment examination was normal along with a normal fundus.

The right eye had normal anterior and posterior segment on examination. BCVA in the right eye was 20/20, N6 and 20/200, N36 in OS. Based on the examination findings, a provisional diagnosis of primary corneoscleral cyst was made.

After obtaining informed consent from the parents, surgical intervention was planned as the cyst covered the pupillary axis. Localized peritomy was performed to expose the underlying scleral cyst. The anterior wall of the cyst was removed by excision of the scleral roof. There was a narrow passage through the limbus, connecting the scleral cyst to the corneal cyst. Fluid was drained from the intrastromal part of the cyst, and the cavity was repeatedly washed with balanced salt solution (BSS). After thorough wash of the intrastromal cavity, the cyst collapsed. The base and sidewalls of the scleral cyst were scrapped to remove the epithelial cells. Bipolar wet-field cautery was used to cauterize the connecting track at the limbus. The partial thickness defect in sclera was covered with the preserved scleral graft to reduce the risk of complication due to scleral thinning. The conjunctiva was closed over it with 8-0 Vicryl sutures. The anterior chamber remained formed throughout the procedure, confirming the absence of communication with the cyst cavity.

Postoperatively, the corneal cyst had collapsed with no recollection of fluid (Fig. 1b, d). The patient was followed up on days 1, 7, and 30, and 3 times monthly thereafter. The last follow-up was 18 months postoperatively. There was no recollection of fluid in the scleral part of the cyst, and the corneal cyst also did not recur. The patient regained BCVA 20/20, N6. Though the optical axis was clear, the affected part of the corneal stroma showed remnants of the debris in form of opacities, which persisted until the last follow-up. The study adhered to the tenets of the Declaration of Helsinki. Histopathological examination of the scrapped wall tissue showed epithelial cells.

\section{Discussion}

Corneoscleral cyst can occur primarily or secondary to trauma or surgery. In the early stage, it may present as intrascleral cyst without corneal component [1-3].

Similar to our case, most of the reported cases showed the cyst wall to be lined with epithelial cells [1,3-5]. Cases of cysts being associated with ghost cells causing hematic cyst and 
presence of lacrimal tissue within the cyst have also been reported $[4,6]$. The origin of these cysts is postulated to be entrapped epithelial cells near the limbus during the scleral development [4].

They begin as intrascleral cyst and later on progress to involve the corneal stroma [3]. Surgical excision is the treatment of choice, though spontaneous resolution of corneal cyst has also been described [7].

Recurrences are known to occur when only the corneal part of the cyst is drained with needle aspiration or a proper removal of the epithelial cells lining the scleral part of the cyst is not done [8,9]. Various chemical methods, aimed at the destruction of epithelial cells have been described in the literature, such as the use of $20 \%$ trichloroacetic acid or cocaine to prevent recurrences $[2,4,8]$. However, these chemical solutions may cause permanent corneal haze by causing stromal scarring. Our case did not have any recurrence until the last follow-up as proper de-roofing was done and the walls of the cyst were scrapped thoroughly to remove all epithelial cells. We used BSS instead of chemical agents to flush the corneal cyst. Presence of intrastromal opacities even after repeated flushing of the cyst with BSS indicates the presence of residual epithelial cells. Similar findings were noted with the use of distilled water by Shin et al. [5]. The use of alternative solutions should be investigated to reduce this complication.

Covering the excised cyst with a lamellar corneal graft, amniotic membrane, the preserved sclera, or the fascia lata reduces the risk of staphyloma formation [1, 6]. Lamellar keratoplasty after excision of a cyst has also been reported [10].

\section{Conclusion}

Corneoscleral cyst represents developmental anomaly and can be treated safely by cyst excision combined with scleral-patch grafting along with irrigating the cyst with BSS. It should be considered in the differential diagnosis of cystic ocular surface disorders in the pediatric age group. The ideal irrigating solution for complete destruction or removal of the lining epithelial cells of cysts needs to be investigated further.

\section{Statement of Ethics}

Institutional ethics committee approval was obtained and the study adhered to the tenets of the Declaration of Helsinki.

\section{Disclosure Statement}

The authors declare that there are no conflicts of interest to disclose.

\section{References}

1 Akbaba M, Hacıyakupoğlu G, Uğuz A, Karslıoğlu Ş, Karcıoğlu Z: Congenital intrascleral cyst. Clin Ophthalmol 2011;5:583-585.

-2 Graubart E, Hubbard GB 3rd: Giant intrascleral cyst treated with trichloroacetic acid. Arch Ophthalmol. 2008;126:438-439.

3 Mahmood MA, Awad A: Congenital corneoscleral epithelial cyst. Am J Ophthalmol 1998;126:741-742. 
Kalamkar and Mukherjee: Primary Corneoscleral Cyst in a Pediatric Patient

\footnotetext{
4 Rao SK, Fogla R, Biswas J, Padmanabhan P: Corneoscleral epithelial cysts: evidence of developmental etiology. Cornea 1998;17:446-450.

5 Shin YJ, Wee WR, Kim M, Lee JH: Corneoscleral cyst treated with distilled water injection. Korean J Ophthalmol 2002;16:110-113.

6 Shah SG, Matalia HP, Sangwan VS: Spontaneous onset corneoscleral hematic cyst. Indian J Ophthalmol 2006;54:118-120.

7 Nikolic LB, jovanovic V, Delevic S: In vivo confocal microscopy of a corneoscleral epithelial cyst after spontaneous marsupialization. Cornea 2013;32:880-882.

8 Reed JW, Dohlman CH: Corneal cysts. Arch Ophthalmol 1971;86:648-652.

-9 Liakos GM: Intracorneal and corneoscleral cysts. Br J Ophthalmol 1978;62:155-158.

$\checkmark 10$ Sano Y, Okamoto S, Nishida K, Sotozono C, Kinoshita S: Peripheral lamellar keratoplasty for corneoscleral cyst: three case reports. Cornea 1999;18:233-236.
}
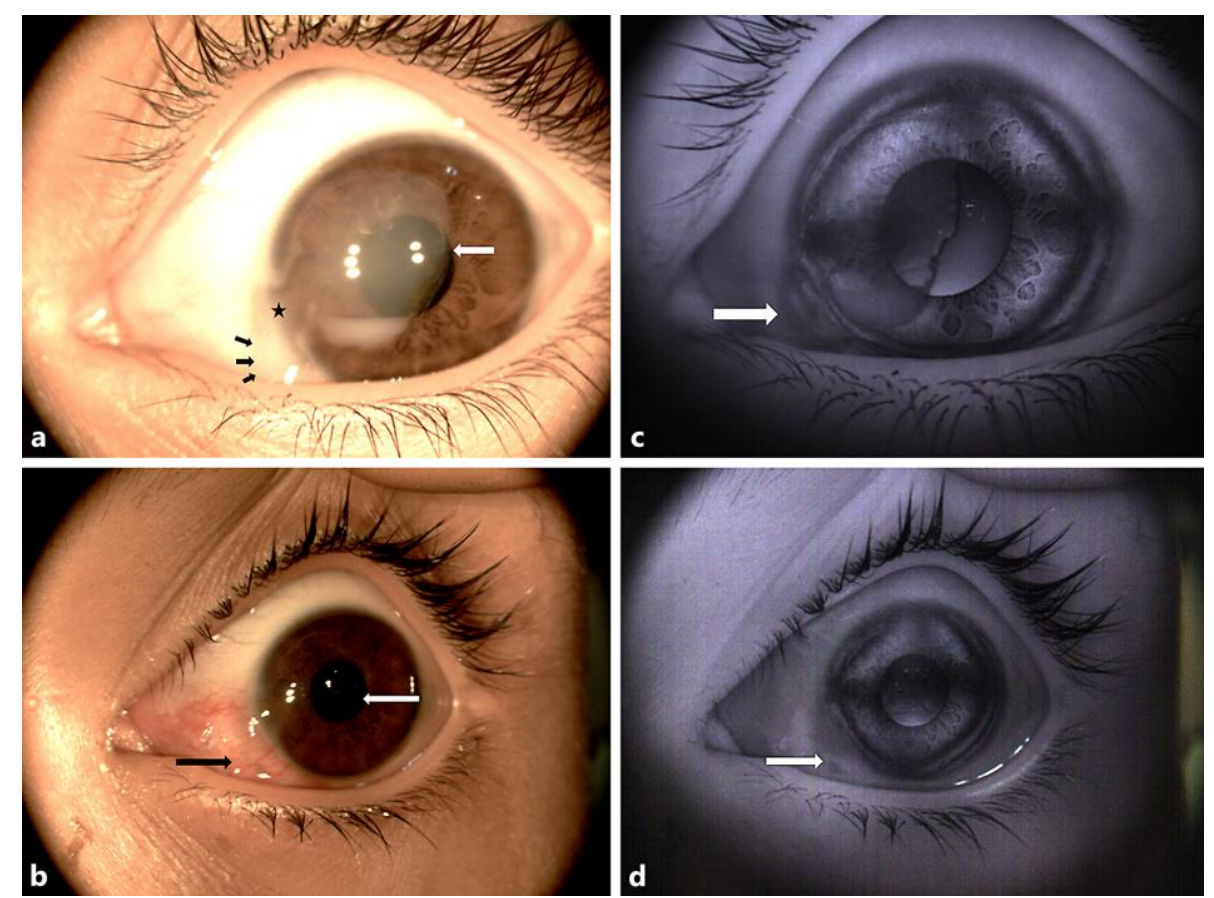

Fig. 1. Anterior segment images of the left eye (color and red free). a Preoperative color image. Intrastromal cyst covering the nasal half of the cornea (white arrow). Scleral part of the cyst (black arrows). Narrow connection between the corneal and scleral parts at the limbus (black star). b Postoperative color image. Collapsed cyst with no fluid (white arrow). De-roofed scleral cyst covered by a scleral graft and the conjunctiva (black arrow). c Preoperative red-free image. Extent of the scleral part of the cyst is clearly seen (white arrow). d Postoperative red-free image. Resolved corneal cyst with a flattened scleral part of the cyst (white arrow). 